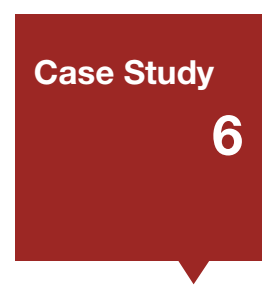

\title{
Raising awareness on RDM and engaging stakeholders in Latin America and the Caribbean
}

\author{
Authors: Gabriela Andaur \& Wouter Schallier (Consultant and Chief of the \\ Hernán Santa Cruz Library, UN Economic Commission for Latin America and \\ the Caribbean [ECLAC])
}

Email: wouter.schallier@cepal.org / gabriela.andaur@cepal.org

\subsection{THE OVERALL CHALLENGE}

Raising awareness among relevant stakeholders is critical for the success of any Research Data Management (RDM) initiative, as their participation and collaboration will be needed for the development and implementation of related policies and programmes. The UN Economic Commission for Latin America and the Caribbean (ECLAC), in its role as a partner institution of the LEARN Project, had as one of its missions to raise awareness and engage RDM stakeholders within Latin America and the Caribbean (LAC).

However, the task constituted a significant challenge due to the geographical dimensions of the region and the socio-cultural diversity within it. For that reason, ECLAC had to develop a strategy that involved several actions, including gathering information about the current state of $L A C$ in regards to RDM; identifying relevant stakeholders; liaising with them to understand their needs and expectations, and planning targeted activities taking into account the particularities of people and institutions within the region.

\subsection{RDM IN LAC: STATE OF THE ART}

The first step was gathering information about past and current developments in RDM in LAC. This would lead to the identification of institutions, people and projects related to research data, in terms of data creation, management, preservation, access, and policy development.

Due to the complexities in collecting information from such a large variety of countries - each one being a whole universe of people and organisations - six countries were selected as the starting point and main focus of research: Argentina, Brazil, Chile, Colombia, Mexico and Peru. Information was gathered using freely-available publications in several formats, mainly institutional websites, and complemented by interviews with stakeholders when necessary.

This initial approach allowed ECLAC to get a first overview of the RDM landscape in LAC. It could be established that - although isolated or relatively unknown - there are several initiatives from scientific communities and organisations related to the management of research data.

One of the trends identified in the region is the promotion of the management of research data through national legal initiatives in the domain of access to scientific information. The most prominent case is Argentina, where the enactment of the law $n^{\circ} 26899^{1}$ in 2013 set new requirements for individuals and organisations whose research is publicly funded and led to the creation of the National System of Repositories 
(SNRD, by its name in Spanish). Other examples are Peru (law $\left.n^{\circ} 30035,2015^{2}\right)$ and Mexico (Reform to Science and Technology law in 20143), where national repositories are expected to gather research publications and data and make them available to the public.

Brazil is another country making progress in the field of RDM, where efforts are being made by organisations related to scientific development. Among them is FAPESP, the funding agency of the Sao Paulo State, currently in the process of developing agency-wide Research Data Management Plans, and the Brazilian Institute of Science and Technology (IBTC), whose Rede Cariniana - a network of digital preservation services available to Brazilian universities - will make available research data generated by researchers in all fields of knowledge.

These are a few examples of initiatives found in the research phase, which also included discipline-specific repositories in a variety of fields such as social sciences, economics and biodiversity. Their identification served as a basis for the definition of the activities that were undertaken by ECLAC in the following months.

\subsection{STAKEHOLDERS IDENTIFICATION}

The identification of stakeholders was undertaken along with the gathering of general information about RDM in LAC. During the process, ECLAC sought to identify people and organisations, taking into consideration two criteria: the representation from, at least, the six selected countries, and the presence of the most relevant professional sectors or roles normally involved in the management of data (such as researchers, librarians, IT professionals, policy makers and research funders). The size of the initial list of stakeholders grew throughout the research (reaching over 400 people), and its quality improved mainly thanks to the collaboration of the same stakeholders, who provided useful references to people and projects within particular fields, sectors and/or countries, thus helping ECLAC to build a credible network of contacts within LAC.

\subsection{UNDERSTANDING STAKEHOLDERS NEEDS AND EXPECTATIONS}

After the main group of stakeholders was defined, over 30 meetings were planned and held, either in person or virtually, with three main objectives in mind: to present the LEARN Project and its goals, to better understand the current state of development of RDM in each country and institution, and to identify the strengths and needs perceived by each stakeholder in this respect.

The meetings proved useful in fulfiling these objectives, although some challenging aspects of working with a diverse group of stakeholders over a large geographic area started to emerge. For example, it became apparent that there was not a single use and understanding of terms related to RDM and the scope and purpose of RDM itself. Moreover, one of the first findings was that Research Data Management was not a commonly used term in LAC, meaning that the difference between RDM and other related terms (such as Open Science, Open Data or Open Access) was not necessarily clear. This was identified as a potential barrier to effective communication with stakeholders.
ECLAC was able to identify different levels of understanding about the implications of RDM and to perceive that stakeholders had different interests and expectations in terms of their collaboration with LEARN. However, they had something in common: they wanted to learn more about RDM and they were also interested in knowing other people and organisations with experience in this area, in particular within the Latin American and Caribbean spectrum. This prompted ECLAC to plan new activities to that end.

\subsection{TARGETED ACTIVITIES}

Having in mind the differences, needs and expectations of stakeholder groups, ECLAC organised a series of online mini-workshops, designed to serve two main purposes: first, to allow stakeholders to meet and know about each others' experience in RDM and, second, to present and discuss issues about the management of research data, which could also help in setting a common understanding of RDM concepts, as a theoretical ground to build upon in future activities.

The first mini-workshop, titled "Research Data Management (RDM): An overview", was held on 20 April, 2016. A second event, more specific in terms of content, was held on 30 June, 2016, and consisted of a discussion of the current state of development of RDM in one Latin American country, Peru. Both events were held using a virtual platform, and lasted one hour.

A third mini-workshop was held in Port of Spain, Trinidad and Tobago, on 24 November, 2016. This event was different from the first two mini-workshops, as it was an on-site full-day event, focused on the developments in and particular characteristics of the Caribbean context.

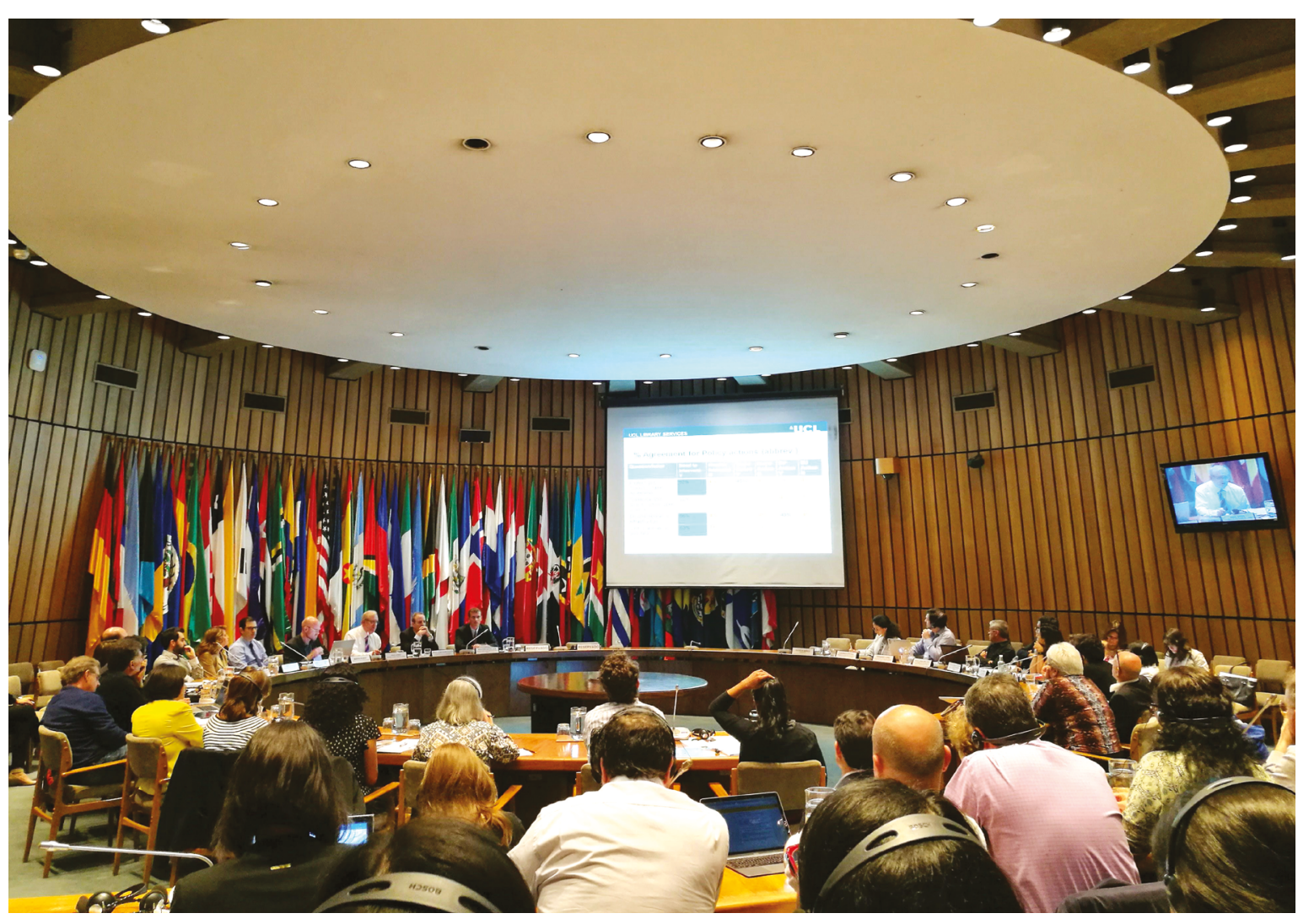

Figure 6.1 LEARN Workshop at UN ECLAC, Santiago, Chile 


\subsection{CREATING A FORUM FOR REGIONAL COLLABORATION}

The participation of ECLAC in the LEARN Project considered, from the beginning, the organisation of one regional event, which was held on 27 October 2016 at the UN ECLAC premises in Santiago, Chile. The event was titled "Implementation of policies and strategies in Latin America and the Caribbean". The programme and activities were strongly tied to the findings of the team in previous activities, and resulted in the gathering of around 90 people representing the regional and professional diversity of stakeholders from Latin American and the Caribbean.

This event, and the three previous mini-workshops, allowed ECLAC to advance in a significant manner its mission of raising awareness on RDM-related issues and engaging stakeholders in Latin America and the Caribbean. They also provided a forum for stakeholders in which they met, learned about other people and organisations' work, shared their experiences and started a discussion about strategic areas of development. It is hoped that these experiences will also contribute to the creation of alliances and joint projects to foster the development of RDM both across LAC and beyond.

\subsection{LESSONS LEARNED}

The experience of ECLAC in raising awareness on RDM throughout Latin America and the Caribbean provided several lessons. First, it proved how important it is to identify stakeholders and to understand their situation and needs prior to the planning of specific actions.

Expectations on each side must be known, as any action will have to take into account what each party can provide and what it expects to receive. In this respect, actions should be taken to make sure that appropriate communication channels in all directions are in place, and to identify potential barriers, such as language, preconceptions on a given topic, or different organisational cultures and procedures, among others.

A diverse pool of stakeholders requires a close examination of each one of them before looking at the big picture. This will help any organisation to deliver a clear message and to plan and execute targeted activities relevant and useful to all RDM stakeholders which will, in turn, encourage their engagement in the management of research data.

This project has received funding from the European Union's Horizon 2020 research and innovation programme under grant agreement No 654139. 